\title{
Caracterização de Junta Soldada por Brasagem de Liga de Níquel-Cromo Uti- lizada como Biomaterial Odontológico
}

\section{Characterization of a Joint Soldered by a Brazing of Nickel-Chromium alloy used as Odontological Biomaterial}

\author{
Artigo \\ Original \\ Original \\ Paper \\ Alexandre Alvarenga Palmeira ${ }^{1}$ \\ Marilia Garcia Diniz ${ }^{2}$ \\ Carlos Antonio Freire Sampaio ${ }^{2}$ \\ Mauro Sayão de Miranda ${ }^{2}$ \\ Cyro Alves Borges Júnior ${ }^{2}$
}

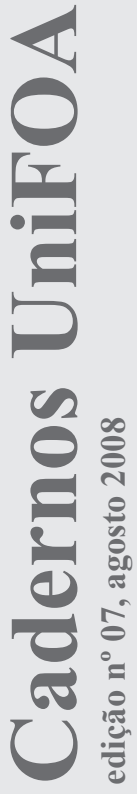

Palavras-chaves:
Biomaterial
Odontológico
Soldagem
Liga de Níquel -
Cromo

Cromo
Key words:

Odontological

Biomaterial

Soldering

Nickel-Chromi-

um Alloy

\footnotetext{
${ }^{1}$ Mestre - Ciências Exatas - Engenharias - UniFOA
}

${ }^{2}$ Doutores - Departamento de Mecânica - UERJ 


\section{Introdução}

Desde 1960, as combinações entre ligas metálicas e porcelanas vêm sendo utilizadas por dentistas para a construção de dispositivos de restauração oral. A combinação entre ligas metálicas em peças fundidas e o revestimento de porcelanas promove uma excelente combinação entre resistência mecânica de uma superestrutura metálica e a aparência estética de dentes de porcelana, criando a ilusão de que as restaurações são verdadeiros dentes. As ligas metálicas têm sido desenvolvidas para formarem uma forte adesão com as porcelanas, com ligações estáveis e duráveis. Várias ligas metálicas não ferrosas têm sido utilizadas para fabricação de próteses dentárias. A escolha dessas ligas se baseia em sua excelente resistência à corrosão e uma boa resistência mecânica, além de não causarem danos, tais como a liberação de elementos citotóxicos (VON RECUM, 1999).

Algumas das ligas metálicas utilizadas para a fabricação das próteses dentárias são à base de níquel e elas apresentam propriedades mecânicas e químicas bastante favoráveis para a construção do referido sistema metal cerâmico (WILLIANS, 1992) .

Os dispositivos odontológicos feitos de ligas à base de níquel são, normalmente, obtidos por processos de fundição por centrifugação e em laboratórios de próteses os quais também realizam o processo de soldagem de pequenas partes que irão compor uma peça que não possa ser obtida em apenas uma etapa de fundição.

Uma prótese dentária deverá apresentar uma distribuição uniforme de forças e uma adaptação a mais perfeita possível, de tal modo que ocorra de forma exata e passiva (SOUZA, 2005). O emprego da soldagem entre os elementos pilares, durante a fase da confecção da estrutura metálica, tem sido um artifício utilizado por grande parte dos cirurgiões-dentistas na solução de problemas de adaptação (JOHNSON, 2006).

O processo de soldagem das ligas à base de níquel é comumente praticado em laboratórios de próteses dentárias, utilizandose maçarico com gás liquefeito de petróleo (GLP) e oxigênio como fonte térmica, metal de adição e fluxo para soldas de liga à base de níquel comercialmente conhecida como FIT [http://www.talladium.com.br, dados obtidos em 15 de agosto de 2006].
Buscando-se cumprir os requisitos para escolha de materiais biocompatíveis, os materiais metálicos apresentam ampla aplicação, e o estudo de suas propriedades mecânicas e dos seus mecanismos de fratura se valida pela importância na obtenção de melhor qualidade e menor custo do material em aplicações odontológicas (SILVER, F. \& DOILLON, C., 1989). Realçando a grande importância na determinação de propriedades mecânicas de biomateriais, este trabalho objetivou caracterizar propriedades mecânicas e metalúrgicas das juntas soldadas pelo processo comumente utilizado pelos laboratórios de próteses dentárias. Esperase conhecer mais sobre as microestruturas geradas e suas propriedades mecânicas na tentativa de propor melhorias futuras para os materiais envolvidos. Foram obtidos os aspectos microestruturais e realizados testes de microdureza nas juntas soldadas pelo método comumente praticado pelos protéticos.

\section{Materiais e Métodos}

O material do presente trabalho é uma liga de níquel, utilizada para fabricação de próteses odontológicas fixas, denominada comercialmente FIT-CAST SB. A composição química ( $\%$ em peso) fornecida pelo fabricante é de $61 \%$ de $\mathrm{Ni}, 25 \%$ de $\mathrm{Cr}, 10,5 \%$ de $\mathrm{Mo}$, 1,5\% de $\mathrm{Si}$ e $\mathrm{Ti}<1 \%$ [http://www.talladium. com.br, 15 de agosto de 2006].

Foram confeccionados três corpos de prova de juntas soldadas, que foram obtidos da união das partes com 2,5mm de diâmetro e $18 \mathrm{~mm}$ de comprimento, dimensões estas, compatíveis com as utilizadas na fabricação das próteses dentárias.

O procedimento de soldagem foi realizado de acordo com as técnicas usuais de laboratório de próteses que incluem as etapas de limpeza da região a ser soldada, fixação das partes envolvidas na soldagem com cera, preparação do revestimento (suporte dos corpos de prova), ajuste da chama ( 8 psi de oxigênio, 5 psi de gás GLP), preparo do fluxo e da vareta de solda. A Tabela 1 apresenta a composição química da vareta de solda e a Tabela 2 apresenta a composição química do fluxo utilizado.

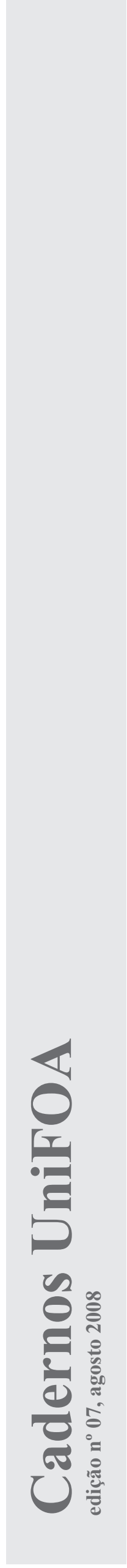


Tabela 1 - Composição química do metal de adição utilizado

\begin{tabular}{|c|c|}
\hline ELEMENTO & PERCENTAGEM EM PESO (\%) \\
\hline Silício & $4-5$ \\
\hline Cromo & $13-15$ \\
\hline Boro & $2,5-3$ \\
\hline Titânio & $0,5-0,7$ \\
\hline Ferro & $1,5-2,5$ \\
\hline Níquel & Restante \\
\hline
\end{tabular}

[http://www.talladium.com.br, 15 de agosto de 2006]

Tabela 2 - Composição química do fluxo utilizado na solda

\begin{tabular}{|l|l|}
\hline COMPOSTO & PERCENTAGEM EM PESO (\%) \\
\hline Potássio Tetra Borato & $40-50$ \\
\hline Ácido Bórico & $40-60$ \\
\hline Farinha de Potássio Borato & $5-14$ \\
\hline
\end{tabular}

[http://www.talladium.com.br, 15 de agosto de 2006]

Os corpos de prova soldados foram embutidos em resina para a obtenção de amostras metalográficas. Em seguida, foram lixadas em lixadeira automática seguindo a seqüência de granulometrias das lixas 80 , 220,440 e 600 . Ao final da etapa de lixamento seguiram-se polimentos com pasta de diamante nas granulometrias $1 \mu \mathrm{m}, 1 / 2 \mu \mathrm{m}$ e $1 / 4 \mu \mathrm{m}$. As amostras foram então atacadas com solução à base de ácido nítrico e fluorídrico. $\mathrm{O}$ ataque foi realizado por dois minutos.

A observação das microestruturas foi feita em um microscópio óptico com captura digital de imagem através de uma câmera digital e software apropriado.

A variação da microdureza ao longo das juntas soldadas foi obtida através de um dispositivo para medida de dureza Vickers acoplado a um microscópio óptico Carl Zeiss - Jena com carga de $0,98 \mathrm{kgf}$ (100g).

\section{Resultados e Discussões}

As Figuras de 1 até 3 apresentam exemplos dos aspectos micrográficos obtidos para as juntas soldadas pelo método utilizado por protéticos. As micrografias obtidas revelaram aspectos típicos de fundição de ligas de níquel para as regiões de metal de base (Figuras 1), em que a estrutura consiste em carbetos precipitados (regiões mais escuras) em formas esféricas e dendríticas em uma matriz rica em níquel (METALS HANDBOOK, 1964).

Um trabalho anterior (PIMENTA, A. R., DINIZ, M. G., SAMPAIO, C. A. F., MIRANDA, M. S., 2006) revelou para o metal de base as presenças significativas de $\mathrm{Mn}$ e $\mathrm{Al}$, detectados por espectroscopia por dispersão de energia. A possível presença do $\mathrm{C}$ foi considerada devido aos aspectos micrográficos obtidos (METALS HANDBOOK, 1964). Os elementos $\mathrm{Mn}, \mathrm{Al}$ e $\mathrm{C}$ não constam nas informações fornecidas pelo fabricante sobre a composição química da liga utilizada, mas sabe-se que pequenas quantidades de carbono já são significativas para a formação de carbetos em ligas de níquel.

As zonas de fusão revelaram-se com uma segunda fase precipitada que variava do esférico ao dendrítico (Figura 2) e uma zona termicamente afetada fazendo uma interface nítidamente distinta da microestrutura do metal de base (Figura 3).

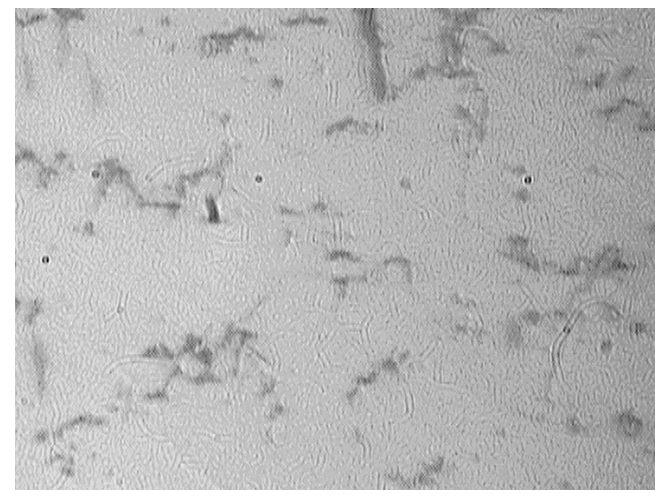

Figura 1 - Aspecto micrográfico do metal de base da liga de níquel-cromo. Ataque HF, aumento 500X.

O processo de soldagem padrão dos protéticos apresentou todas as características de uma brasagem. Sabe-se que a temperatura alcançada $\left(<450^{\circ} \mathrm{C}\right)$ é muito menor que a de fusão da liga Ni-Cr utilizada como metal de base. Existe uma significativa quantidade de boro no material utilizado como fluxante, também indicativo de processo de brasagem (METALS HANDBOOK, 1964).

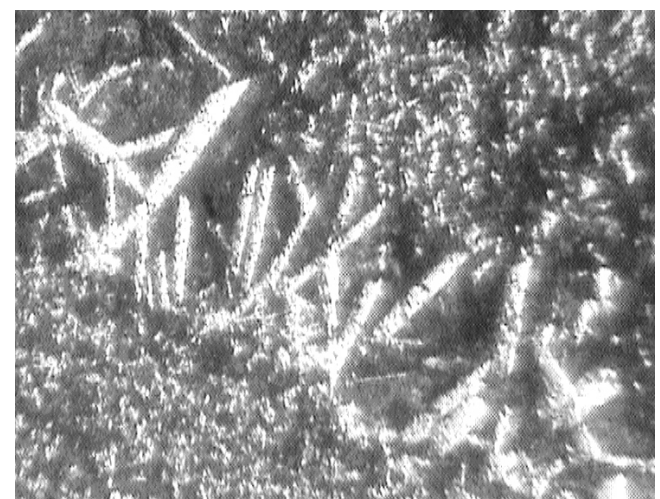

Figura 2 - Aspecto micrográfico da zona de fusão da junta soldada. Ataque HF, aumento 380X. 
Nota-se uma diferença significativa entre os tamanhos e geometrias dos carbetos precipitados no metal de base e os tamanhos e geometrias da fase dendrítica da zona de fusão. Essa diferença poderá provocar uma grande heterogeneidade no comportamento mecânico entre as regiões soldada e o restante da peça.

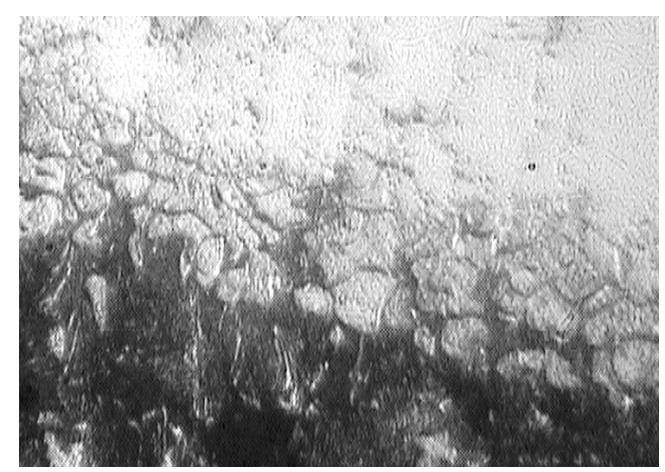

Figura 3 - Aspecto micrográfico da zona termicamente afetada (ZTA) da junta soldada. Ataque: HF, aumento: $500 \mathrm{X}$.

A Figura 4 exemplifica os comportamentos obtidos de variação da microdureza Vickers para as regiões das juntas soldadas. A posição 1 refere-se à região central do cordão de solda, a posição 2 é a de interface entre o metal levado a fusão durante o processo e o metal de base e, finalmente, a posição 3 representa regiões do metal de base não afetadas pelo calor (longínquas). A curva da regressão mostra uma tendência de aumento da microdureza ao longo da região soldada.

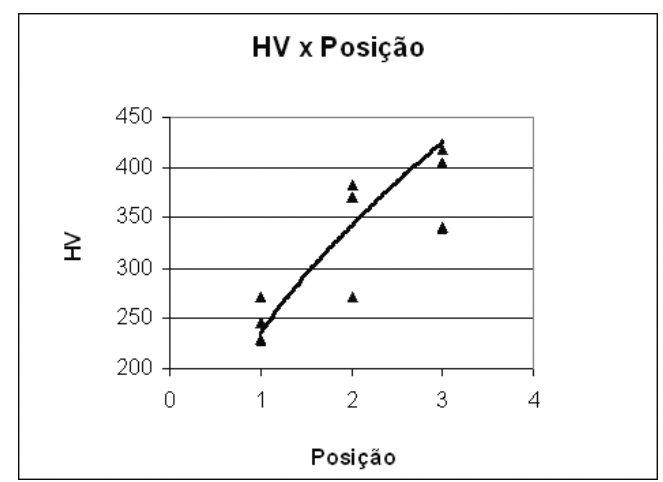

Figura 4 - Variação da microdureza (HV) ao logo de uma junta soldada pelo método usual de fabricação de próteses odontológicas de liga à base de níquel-cromo.

\section{Conclusões}

O processo de soldagem por brasagem, comumente utilizado por laboratórios de próteses odontológicas, gerou grandes diferenças microestruturais entre a junta soldada e o metal de base. Variações significativas também ocorreram com a microdureza ao logo da região de solda. Isso poderá significar uma má distribuição de tensões nos dispositivos dentários de liga à base de Ni-Cr e levá-los a possíveis falhas por fratura.

\section{Referências}

JOHnSON, C., An Overview of The Types of Arc Welding, disponível em www.bsu.edu/ web/cwjohnson2/welding.html, acesso em 23 de janeiro de 2006 .

METALS HANDBOOK, 8a edição, vol. 7, ASM Handbook Committee American Society for Metals, Metals Park, Ohio, 44073, 1964.

SILVER,F.\&DOILLON,C.,Biocompatibility, VCH Publishers Inc., New York, USA, 1989.

PIMENTA, A. R., DINIZ, M. G., SAMPAIO, C. A. F.; MIRANDA, M. S., In: XIII Congresso Nacional de Estudantes de Engenharia Mecânica, Anais do XIII Congresso Nacional de Estudantes de Engenharia Mecânica, 2006.

SOUZA, L. L. de, Caracterização Microestrutural e Resistência à Corrosão de Ligas Ni-Cr-Mo Refundidas Utilizadas em Próteses Dentárias, Dissertação de Mestrado, Faculdade de Engenharia de Guaratinguetá, UNESP, São Paulo, 2005.

VON RECUM, ANDREAS F., editor, Handbook of Biomaterials Evaluation, 2a edição, Taylor \& Francis, London, 1999.

WILlians, D. F., Medical and Dental Materials, VCH Publishers Inc., New York, USA, 1992.

Endereço para Correspondência:

Prof. Alexandre Alvarenga Palmeira

Cursos de Engenharias

alexandre.palmeira@foa.org.br

Centro Universitário de Volta Redonda

Campus Três Poços

Av. Paulo Erlei Alves Abrantes, $n^{\circ}$ 1325,

Três Poços - Volta Redonda / RJ

CEP: $27240-560$ 